\title{
USING THE ANALYTIC HIERARCHY PROCESS TO PRIORITIZE AND SELECT PHASE CHANGE MATERIALS FOR COMFORT APPLICATION IN BUILDINGS
}

\author{
LAVINIA GABRIELA SOCACIU - Assistant Professor, PhD, Technical University of Cluj-Napoca, Faculty of \\ Mechanical Engineering, e-mail: lavinia.socaciu@termo.utcluj.ro \\ PAULA VERONICA UNGURESAN - Lecturer, PhD, Technical University of Cluj-Napoca, Faculty of \\ Mechanical Engineering, e-mail: paula.unguresan@termo.utcluj.ro
}

\begin{abstract}
Phase change materials (PCMs) selection and prioritization for comfort application in buildings have a significant contribution to the improvement of latent heat storage systems. PCMs have a relatively large thermal energy storage capacity in a temperature range close to their switch point. PCMs absorb energy during the heating process as phase change takes place and release energy to the environment in the phase change range during a reverse cooling process. Thermal energy storage systems using PCMs as storage medium offer advantages such as: high heat storage capacity and store/release thermal energy at a nearly constant temperature, relative low weight, small unit size and isothermal behaviour during charging and discharging when compared to the sensible thermal energy storage. PCMs are valuable only in the range of temperature close to their phase change point, since their main thermal energy storage capacity depend on their mass and on their latent heat of fusion. Selection of the proper PCMs is a challenging task because there are lots of different materials with different characteristics. In this research paper the principles and techniques of the Analytic Hierarchy Process (AHP) are presented, discussed and applied in order to prioritize and select the proper PCMs for comfort application in buildings. The AHP method is used for solving complex decisional problems and allows the decision maker to take the most suitable decisions for the problem studied. The results obtained reveal that the AHP method can be successfully applied when we want to choose a PCM for comfort application in buildings.
\end{abstract}

Keywords: Phase change material (PCM), Analytic hierarchy process (AHP), Selection and prioritization of PCMs.

\section{Introduction}

Since 1980, phase change materials (PCMs) have been considered for thermal storage in buildings. In recent years, the use of PCM in buildings has gained interest of researchers around the world.

PCM is a substance with a high heat of fusion which melts and solidifies at certain temperatures [1]. PCM is capable of storing or releasing large amounts of latent heat of fusion [2]. When solar radiation is available, the heat energy obtained from the solar receiver can be stored in the PCM by changing the phase of the PCM from solid to liquid, which is called the charging process [1]. Later on, during cloudy periods or over the night, the stored heat can be recovered and used for increasing thermal comfort. During the discharging process, the PCM is changing the phase from liquid to solid. Latent heat is absorbed or released when the material is melting or solidifying respectively [3]. This gives the material an extra heat storing capacity if its melting point is located within the working temperature [3].

The effects of the use of PCM in buildings can be stated in many different ways: increased thermal comfort (air thermal peak reduction, decrease of daily temperature swing, changing in surface temperature), improved building envelope (insulation capacity, change in heat flow through them), decrease the conditioning power needed, increased systems efficiency, reducing energy demand, off peak energy savings, among others [4]. 
The application of PCMs in buildings can have two different goals: first, using natural heat that is solar energy for heating or night cool for cooling; second, using manmade heat or cold sources. PCM can be used in trombe-wall, wallboards, shutters, under-floor heating systems and ceiling boards can be use as part of the building for heating and cooling applications [5].

According to [6] the main criteria that govern the selection of PCMs are: possess a melting temperature in the desired operating temperature range of application; possess a high latent heat capacity per unit mass, so that a smaller amount of material stores a given amount of energy; high specific heat capacity to provide additional significant sensible heat storage effects; high thermal conductivity, so that the temperature gradients for charging and discharging the storage material are small; small volume changes during phase transition, so that a simple container and heat exchanger geometry can be used; exhibit little or no sub cooling during freezing; possess chemical stability, no chemical decomposition and corrosion resistance to construction materials; contain non-poisonous, non-flammable and non-explosive elements/compounds; available in large quantities at low cost.

Specialised literature does not treat the selection of proper PCMs for comfort application in buildings using analytic hierarchy process, or other multi attribute decision making, although the reviews of the material used as PCM in thermal energy storage in buildings and their applications are presented. Therefore we could identify only one paper [3], in the specialised literature, where authors evaluate the best choice of PCM used in solar domestic hot water system using TOPSIS and Fuzzy TOPSIS method [3]. These two methods are techniques used to order preference by similarity to ideal solution [3]. Both approaches use an analytic hierarchy process (AHP) method to determine weights of the criteria [3]. TOPSIS and Fuzzy TOPSIS methods are used to obtain the final ranking [3].

The purpose of this study was to find the proper alternative of phase change materials applied for comfort applications in buildings. The used method in order to reach the purpose was the Analytic Hierarchy Process (AHP), which is a powerful and flexible tool for multiple attribute decision making tactics for prioritising and best decision taking. Applying the AHP method for prioritization and selection of the proper commercial PCMs for comfort application in buildings is a new approach in this field.

\section{The Analytic Hierarchy Process}

The Analytic Hierarchy Process (AHP) is a decision support tool developed by Saaty [7], in which tangible and intangible factors are qualified based on subjective criteria to provide a numeric scale for prioritizing decision alternatives [8]. Instead of decision making, AHP offers a result, which is the best suitable answer for the studied problem. The steps to be followed for an AHP model are [9-10]:

Step 1: Construct the decision matrix. Each element of the matrix is based on Saaty`s nine-point scale presented in table 1 . The comparison matrix reflects the decision maker's judgment regarding relative importance of different criteria. The pair-wise comparison is made so that the criterion in row $i(i=1,2, \ldots, n)$ is ranked relative to each of the criteria represented by the $n$ columns. $\mathrm{G}$ is the evaluation matrix (nxn) obtained from the pair-wise comparison. The element gij $(i, j=1,2, \ldots, n)$ indicates the relative importance of criterion $i$ respecting criterion $j$. A criterion compared with itself is always assigned the value 1 so the main diagonal entries of the pair-wise comparison matrix are all 1 [3].

$$
G=\left[\begin{array}{cccc}
1 & g_{12} & \cdots & g_{1 n} \\
g_{21} & 1 & \cdots & g_{2 n} \\
\cdots & \cdots & \cdots & \cdots \\
g_{n 1} & g_{n 2} & \cdots & 1
\end{array}\right], g_{i j} \neq 0 \text { and } g_{j i}=1 / g_{i j}
$$


The nine-point scale of pair-wise comparison [3]

\begin{tabular}{|c|c|}
\hline Intensity of relative importance & Definition \\
\hline 1 & Equally important \\
\hline 3 & Moderately important \\
\hline 5 & Strongly important \\
\hline 7 & Very strongly important \\
\hline 9 & Extremely important \\
\hline $2,4,6,8$ & Intermediate judgment between two adjacent judgments \\
\hline
\end{tabular}

Step 2: Develop a normalized matrix by dividing each number from the column of the pair-wise comparison matrix by its column sum.

Step 3: Average each row of the normalized matrix. These row averages form the relative weight $\mathrm{w}_{\mathrm{i}}(\mathrm{i}=1,2, \ldots, \mathrm{n})$ of alternative preferences respecting each criterion.

Step 4: To verify if the level of consistency is reasonable, it is needed to develop a quantifiable for the comparison matrix. If $\mathrm{w}$ is the column vector of the relative weight, comparison matrix $\mathrm{G}$ is consistent if:

$$
\mathrm{G} \cdot \mathrm{W}=\mathrm{n} \cdot \mathrm{W}
$$

Matrix $\mathrm{X}$ denotes an $\mathrm{n}$-dimensional column vector. It represents the weighted sum of each alternative considered separately and taking into account each criterion:

$$
\mathrm{X}=\mathrm{G} \cdot \mathrm{W}=\left[\begin{array}{cccc}
1 & \mathrm{~g}_{12} & \cdots & \mathrm{g}_{1 \mathrm{n}} \\
\mathrm{g}_{21} & 1 & \cdots & \mathrm{g}_{2 \mathrm{n}} \\
\cdots & \cdots & \cdots & \cdots \\
\mathrm{g}_{\mathrm{n} 1} & \mathrm{~g}_{\mathrm{n} 2} & \cdots & 1
\end{array}\right] \cdot\left[\begin{array}{c}
\mathrm{w}_{1} \\
\mathrm{w}_{2} \\
\cdots \\
\mathrm{w}_{\mathrm{n}}
\end{array}\right]=\left[\begin{array}{c}
\mathrm{c}_{1} \\
\mathrm{c}_{2} \\
\cdots \\
\mathrm{c}_{\mathrm{n}}
\end{array}\right]
$$

Step 5: Calculate the consistency values (CV) for the cluster of alternatives represented by the vector [3]:

$$
\mathrm{CV}_{\mathrm{i}}=\mathrm{n} \cdot \frac{\mathrm{c}_{\mathrm{i}}}{\mathrm{w}_{\mathrm{i}}}
$$

Step 6: Calculate the eigenvalue $\lambda_{\max }$ :

$$
\lambda_{\text {max }}=\frac{\sum_{\mathrm{i}=1}^{\mathrm{i}=\mathrm{C}_{\mathrm{i}}}}{\mathrm{n}}
$$

Step 7: Calculate the consistency index (CI). It should be noted that the quality of the out of the AHP method is strictly related to the consistency of the pair wise comparison judgments [3].

$$
\mathrm{CI}=\frac{\left(\lambda_{\max }-\mathrm{n}\right)}{\mathrm{n}-1}
$$

Step 8: Calculate the random inconsistency (RI) with:

$$
\mathrm{RI}=\frac{1.987(\mathrm{n}-2)}{\mathrm{n}}
$$

Step 9: Calculate the consistency ratio (CR) with:

$$
\mathrm{CR}=\mathrm{CI} / \mathrm{RI}
$$

The number 0.1 is the accepted upper limit for CR [3]. If the final consistency ratio exceeds this value, the evaluation procedure has to be repeated to improve consistency [3]. The measurement of consistency can be use to evaluate the consistency of decision maker as well as the consistency of overall hierarchy [9-10]. 


\section{Case study}

The aim of this case study is to decide which is the proper commercial PCM used for comfort application in buildings. The PCMs which can be used in the above system should have phase change temperature between 22 and $28^{\circ} \mathrm{C}$. The criteria used in this case study are: phase change temperature (PCT), latent heat capacity (LHC), density for solid phase (DFS), specific heat capacity (SHC), and thermal conductivity of material (TCM). These criteria affect the prioritization and selection of commercial PCM used for comfort application in buildings. For following criteria: latent heat capacity, density for solid phase, specific heat capacity and thermal conductivity of material higher values are preferred. In present case study, eight commercial PCMs for comfort application in buildings were investigated. The alternatives are: Climsel C24 from Climator (Alt 1), PlusIce PCM S27 (Alt 2), PlusIce PCM S23 (Alt 3), PlusIce PCM A22H (Alt 4), PlusIce PCM A26 (Alt 5) from EPS Ltd, RT27 (Alt 6) and RT28 HC (Alt 7) from Rubitherm Gmbh and PCM Latest TM $25 \mathrm{~T}$ (Alt 8) from TEAP. Figure 1 illustrated the proposed hierarchical model based on AHP method and table 2 presented the properties of PCMs studied for comfort applications in buildings.

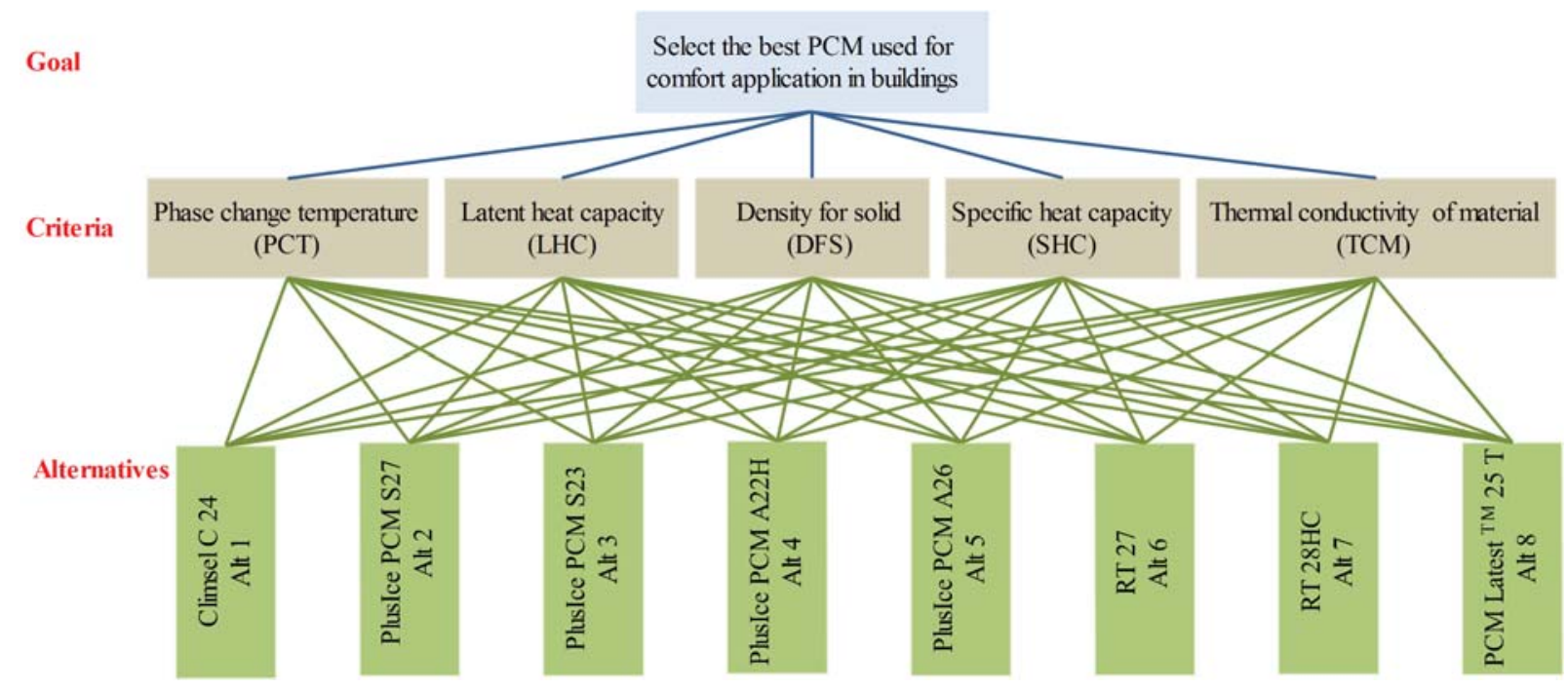

Fig. 1- The proposed hierarchical model based on AHP method

Table 2

The properties of PCMs studied for comfort applications in buildings

\begin{tabular}{|l|c|c|c|c|c|c|c|c|}
\hline \multicolumn{1}{|c|}{ Alternative } & Alt 1 & Alt 2 & Alt 3 & Alt 4 & Alt 5 & Alt 6 & Alt 7 & Alt 8 \\
\hline PCM & $\begin{array}{c}\text { Clim- } \\
\text { sel C 24 }\end{array}$ & $\begin{array}{c}\text { PlusIce } \\
\text { PCM } \\
\text { S27 }\end{array}$ & $\begin{array}{c}\text { PlusIc } \\
\text { e PCM } \\
\text { S23 }\end{array}$ & $\begin{array}{c}\text { PlusIce } \\
\text { PCM } \\
\text { A22H }\end{array}$ & $\begin{array}{c}\text { PlusIce } \\
\text { PCM } \\
\text { A26 }\end{array}$ & RT 27 & $\begin{array}{c}\text { RT } \\
28 H C\end{array}$ & $\begin{array}{c}\text { PCM } \\
\text { Latest } \\
\text { TM }\end{array}$ \\
\hline Source & $\begin{array}{c}\text { Clima- } \\
\text { tor }\end{array}$ & $\begin{array}{c}\text { EPS } \\
\text { Ltd. }\end{array}$ & $\begin{array}{c}\text { EPS } \\
\text { Ltd. }\end{array}$ & $\begin{array}{c}\text { EPS } \\
\text { Ltd. }\end{array}$ & $\begin{array}{c}\text { EPS } \\
\text { Ltd. }\end{array}$ & $\begin{array}{c}\text { Rubi- } \\
\text { therm }\end{array}$ & $\begin{array}{c}\text { Rubi- } \\
\text { therm }\end{array}$ & TEAP \\
\hline $\begin{array}{l}\text { Phase change temperature (PCT) } \\
{\left[{ }^{\circ} \mathrm{C}\right]}\end{array}$ & 24 & 27 & 23 & 22 & 26 & 27 & 28 & 25 \\
\hline $\begin{array}{l}\text { Latent heat capacity (LHC) } \\
{[\mathrm{kJ} / \mathrm{kg}]}\end{array}$ & 108 & 183 & 175 & 216 & 150 & 184 & 245 & 175 \\
\hline $\begin{array}{l}\text { Density for solid (DFS) } \\
{\left[\mathrm{kg} / \mathrm{m}^{3}\right]}\end{array}$ & 1380 & 1530 & 1530 & 820 & 790 & 880 & 880 & 1480 \\
\hline $\begin{array}{l}\text { Specific heat capacity (SHC) } \\
{[\mathrm{kJ} / \mathrm{kgK}]}\end{array}$ & 3.6 & 2.2 & 2.2 & 2.22 & 2.85 & 1.84 & 1.65 & 2.0 \\
\hline $\begin{array}{l}\text { Thermal conductivity of material } \\
\text { (TCM) [W/mK }]\end{array}$ & 0.7 & 0.54 & 0.54 & 0.21 & 0.18 & 0.2 & 0.2 & 1 \\
\hline References & {$[11-12]$} & {$[13]$} & {$[13]$} & {$[13]$} & {$[13]$} & {$[14-15]$} & {$[14-16]$} & {$[17]$} \\
\hline
\end{tabular}


The decision makers use the following assignments for PCM selection: latent heat capacity (LHC) is considered extremely important than phase change temperature (PCT), which means that value 9 is of relative importance for PCT compared with LHC (i.e. g12=9) and the value 1/9 is of relative importance for LHC compared with PCT (i.e. g21=1/9). Specific heat capacity (SHC) is considered to have a stronger importance than thermal conductivity of material (TCM), which means that value 5 is of relative importance for TCM compared with SHC (i.e. g54=5) and the value $1 / 5$ is of relative importance for SHC compared with TCM (i.e. g45=1/5). In a similar manner the relative importance of other criteria can be explained. The decision matrix for the criteria used in this study is:

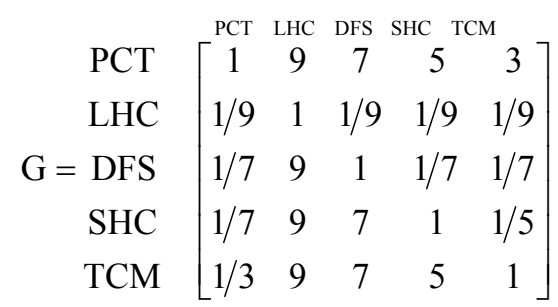

The decision matrix of eight alternatives respecting the criteria used in this study is:

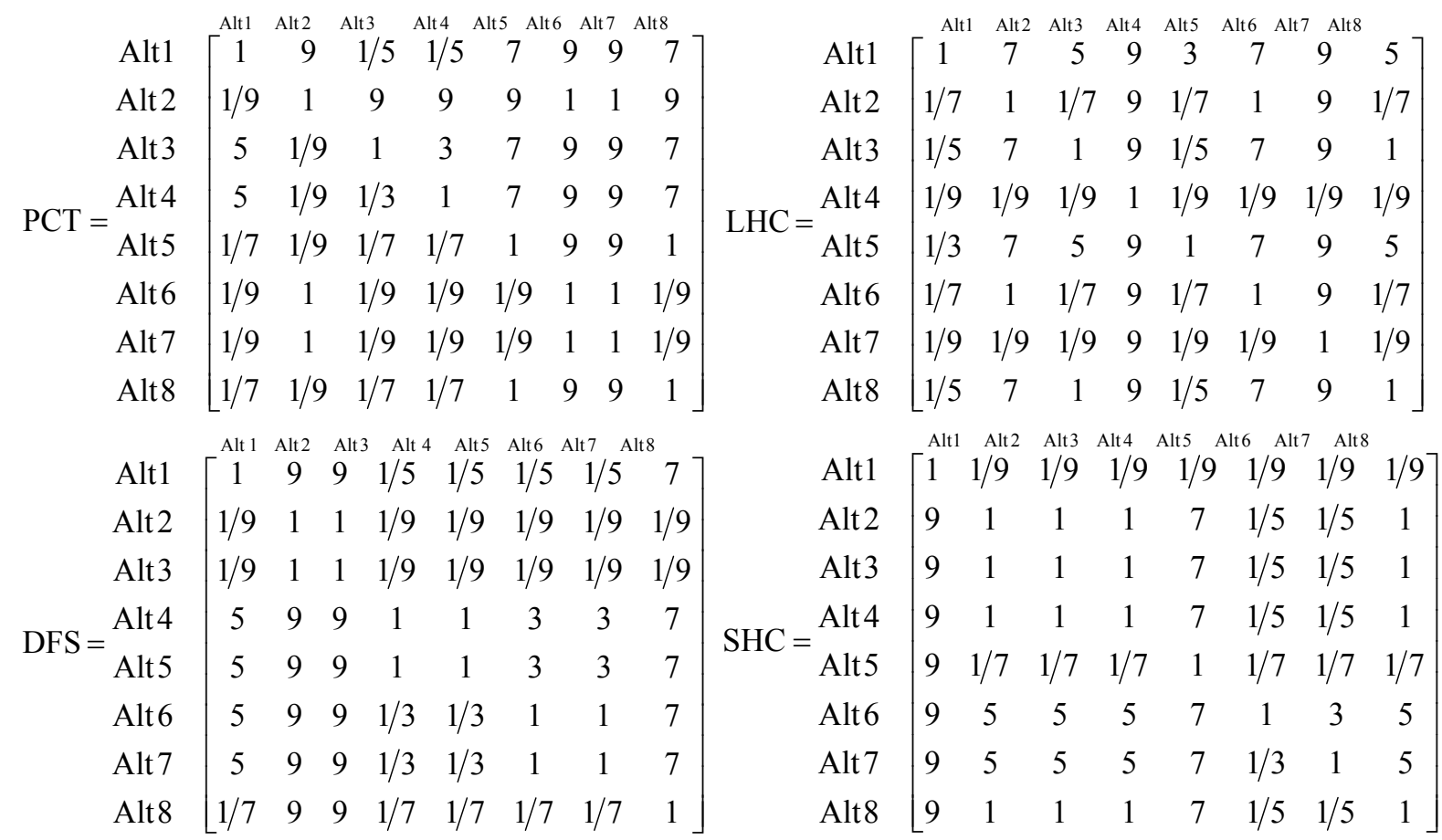

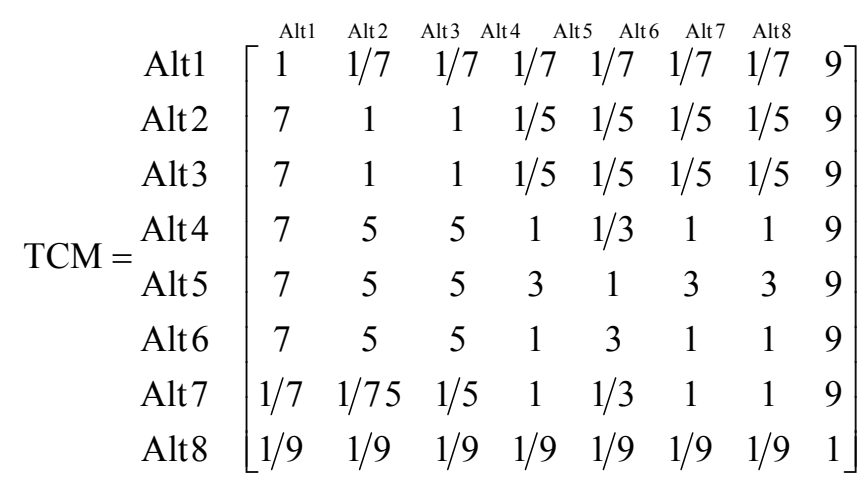

\section{Results and discussion}

Results reached from pair-wise comparison matrix are given in table 3 and 4 . In figure 2 the local weights obtained by using each criteria of the case study are illustrated. Table 5 presents the final results of the case study considered, i.e. the global priority for each alternative 
respecting all five criteria: PCT, LHC, DFS, SHC and TCM. Figure 3 presents the global weights for the alternative.

Table 3

Results obtained from pair-wise comparison matrix of alternatives respecting each criterion

\begin{tabular}{|c|c|c|c|c|c|c|c|c|c|c|c|c|c|c|c|}
\hline \multicolumn{16}{|c|}{ Normalized matrix } \\
\hline & it 1 & Alt 2 & Alt 3 & Alt 4 & Alt 5 & Alt 6 & Alt 7 & Alt 8 & $\mathrm{Wr}$ & $\mathrm{c}$ & \multirow[t]{2}{*}{$\mathrm{CV}$} & \multirow{2}{*}{ 苑 } & \multirow[t]{2}{*}{ ひ } & \multirow{2}{*}{$\widetilde{\simeq}$} & \multirow{2}{*}{ 㞯 } \\
\hline \multicolumn{11}{|c|}{ The criteria PCT: Phase Change Temperature } & & & & & \\
\hline Alt 1 & 0,086 & 0,723 & 0,018 & 0,015 & 0,217 & 0,188 & 0,188 & 0,217 & $20,64 \%$ & 0,25 & 1,22 & \multirow{8}{*}{$\begin{array}{l}\text { J } \\
\stackrel{0}{i} \\
i\end{array}$} & & \multirow{8}{*}{ 志 } & \multirow{8}{*}{$\begin{array}{l}\frac{\infty}{\delta} \\
\frac{1}{1}\end{array}$} \\
\hline Alt 2 & 0,010 & 0,080 & 0,815 & 0,657 & 0,279 & 0,021 & 0,021 & 0,279 & $27,02 \%$ & 0,33 & 1,21 & & & & \\
\hline Alt 3 & 0,430 & 0,009 & 0,091 & 0,219 & 0,217 & 0,188 & 0,188 & 0,217 & $19,48 \%$ & 0,18 & 0,92 & & & & \\
\hline Alt 4 & 0,430 & 0,009 & 0,030 & 0,073 & 0,217 & 0,188 & 0,188 & 0,217 & $16,90 \%$ & 0,14 & 0,85 & & & & \\
\hline Alt 5 & 0,012 & 0,009 & 0,013 & 0,010 & 0,031 & 0,188 & 0,188 & 0,031 & $6,02 \%$ & 0,02 & 0,34 & & & & \\
\hline Alt 6 & 0,010 & 0,080 & 0,010 & 0,008 & 0,003 & 0,021 & 0,021 & 0,003 & $1,96 \%$ & 0,03 & 1,44 & & & & \\
\hline Alt 7 & 0,010 & 0,080 & 0,010 & 0,008 & 0,003 & 0,021 & 0,021 & 0,003 & $1,96 \%$ & 0,03 & 1,44 & & & & \\
\hline Alt 8 & 0,012 & 0,009 & 0,013 & 0,010 & 0,031 & 0,188 & 0,188 & 0,031 & $6,02 \%$ & 0,02 & 0,34 & & & & \\
\hline \multicolumn{16}{|c|}{ The criteria LHC: Latent Heat Capacity } \\
\hline Alt 1 & 0,446 & 0,232 & 0,400 & 0,141 & 0,611 & 0,232 & 0,163 & 0,400 & $32,80 \%$ & 0,43 & 1,32 & \multirow{8}{*}{$\begin{array}{l}\stackrel{\sim}{\tilde{N}} \\
\stackrel{N}{N}\end{array}$} & & \multirow{8}{*}{ 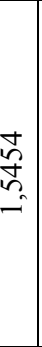 } & \multirow{8}{*}{$\begin{array}{l}0 \\
2 \\
0 \\
0 \\
0\end{array}$} \\
\hline Alt 2 & 0,064 & 0,033 & 0,011 & 0,141 & 0,029 & 0,033 & 0,163 & 0,011 & $6,07 \%$ & 0,04 & 0,69 & & & & \\
\hline Alt 3 & 0,089 & 0,232 & 0,080 & 0,141 & 0,041 & 0,232 & 0,163 & 0,080 & $13,21 \%$ & 0,10 & 0,72 & & & & \\
\hline Alt 4 & 0,050 & 0,004 & 0,009 & 0,016 & 0,023 & 0,004 & 0,002 & 0,009 & $1,44 \%$ & 0,02 & 1,72 & & & & \\
\hline Alt 5 & 0,149 & 0,232 & 0,400 & 0,141 & 0,204 & 0,232 & 0,163 & 0,400 & $23,99 \%$ & 0,24 & 0,99 & & & & \\
\hline Alt 6 & 0,064 & 0,033 & 0,011 & 0,141 & 0,029 & 0,033 & 0,163 & 0,011 & $6,07 \%$ & 0,04 & 0,69 & & & & \\
\hline Alt 7 & 0,050 & 0,004 & 0,009 & 0,141 & 0,023 & 0,004 & 0,018 & 0,009 & $3,20 \%$ & 0,03 & 0,85 & & & & \\
\hline Alt 8 & 0,089 & 0,232 & 0,080 & 0,141 & 0,041 & 0,232 & 0,163 & 0,080 & $13,21 \%$ & 0,10 & 0,72 & & & & \\
\hline \multicolumn{16}{|c|}{ The criteria DFS: Density For Solid } \\
\hline Alt 1 & 0,047 & 0,161 & 0,161 & 0,062 & 0,062 & 0,023 & 0,023 & 0,193 & $9,15 \%$ & 0,06 & 0,66 & & & & \\
\hline Alt 2 & 0,005 & 0,018 & 0,018 & 0,034 & 0,034 & 0,013 & 0,013 & 0,003 & $1,73 \%$ & 0,02 & 1,32 & & & & \\
\hline Alt 3 & 0,005 & 0,018 & 0,018 & 0,034 & 0,034 & 0,013 & 0,013 & 0,003 & $1,73 \%$ & 0,02 & 1,32 & & & & \\
\hline Alt 4 & 0,234 & 0,161 & 0,161 & 0,309 & 0,309 & 0,350 & 0,350 & 0,193 & $25,85 \%$ & 0,30 & 1,17 & $\hat{m}$ & $\infty$ & 㫄 & กิ \\
\hline Alt 5 & 0,234 & 0,161 & 0,161 & 0,309 & 0,309 & 0,350 & 0,350 & 0,193 & $25,85 \%$ & 0,30 & 1,17 & 2 & $\begin{array}{l}0 \\
0 \\
1\end{array}$ & $\stackrel{n}{-}$ & : \\
\hline Alt 6 & 0,234 & 0,161 & 0,161 & 0,103 & 0,103 & 0,117 & 0,117 & 0,193 & $14,86 \%$ & 0,13 & 0,85 & & & & \\
\hline Alt 7 & 0,234 & 0,161 & 0,161 & 0,103 & 0,103 & 0,117 & 0,117 & 0,193 & $14,86 \%$ & 0,13 & 0,85 & & & & \\
\hline Alt 8 & 0,007 & 0,161 & 0,161 & 0,044 & 0,044 & 0,017 & 0,017 & 0,028 & $5,97 \%$ & 0,04 & 0,60 & & & & \\
\hline The c1 & . & . spec & Har en & & & & & & & & & & & & \\
\hline Alt 1 & 0,016 & 0,008 & 0,008 & 0,008 & 0,003 & 0,047 & 0,022 & 0,008 & $1,47 \%$ & 0,02 & 1,66 & & & & \\
\hline Alt 2 & 0,141 & 0,070 & 0,070 & 0,070 & 0,162 & 0,084 & 0,040 & 0,070 & $8,84 \%$ & 0,07 & 0,81 & & & & \\
\hline Alt 3 & 0,141 & 0,070 & 0,070 & 0,070 & 0,162 & 0,084 & 0,040 & 0,070 & $8,84 \%$ & 0,07 & 0,81 & & & & \\
\hline Alt 4 & 0,141 & 0,070 & 0,070 & 0,070 & 0,162 & 0,084 & 0,040 & 0,070 & $8,84 \%$ & 0,07 & 0,81 & $\hat{a}$ & ఫे & 苞 & $\frac{0}{0}$ \\
\hline Alt 5 & 0,141 & 0,010 & 0,010 & 0,010 & 0,023 & 0,060 & 0,028 & 0,010 & $3,65 \%$ & 0,03 & 0,93 & 2 & $\begin{array}{l}0 \\
0 \\
0\end{array}$ & $\stackrel{n}{=}$ & 0 \\
\hline Alt 6 & 0,141 & 0,351 & 0,351 & 0,351 & 0,162 & 0,419 & 0,594 & 0,351 & $33,98 \%$ & 0,43 & 1,25 & & & & \\
\hline Alt 7 & 0,141 & 0,351 & 0,351 & 0,351 & 0,162 & 0,140 & 0,198 & 0,351 & $25,55 \%$ & 0,23 & 0,90 & & & & \\
\hline Alt 8 & 0,141 & 0,070 & 0,070 & 0,070 & 0,162 & 0,084 & 0,040 & 0,070 & $8,84 \%$ & 0,07 & 0,81 & & & & \\
\hline The $\mathrm{cl}$ & ria $\mathrm{TC}$ & I: Thern & Conduc & vity of $\mathrm{N}$ & rial & & & & & & & & & & \\
\hline Alt 1 & 0,023 & 0,006 & 0,006 & 0,021 & 0,054 & 0,021 & 0,021 & 0,141 & $3,69 \%$ & 0,03 & 0,85 & & & & \\
\hline Alt 2 & 0,162 & 0,045 & 0,045 & 0,030 & 0,075 & 0,030 & 0,030 & 0,141 & $6,98 \%$ & 0,05 & 0,76 & & & & \\
\hline Alt 3 & 0,162 & 0,045 & 0,045 & 0,030 & 0,075 & 0,030 & 0,030 & 0,141 & $6,98 \%$ & 0,05 & 0,76 & & & & \\
\hline Alt 4 & 0,162 & 0,225 & 0,225 & 0,150 & 0,126 & 0,150 & 0,150 & 0,141 & $16,61 \%$ & 0,15 & 0,92 & $\tilde{O}$ & ป & $\stackrel{t}{7}$ & $\stackrel{\wp}{\Xi}$ \\
\hline Alt 5 & 0,162 & 0,225 & 0,225 & 0,451 & 0,377 & 0,451 & 0,451 & 0,141 & $31,02 \%$ & 0,38 & 1,23 & $\infty$ & $\mid$ & $\stackrel{n}{n}$ & 0 \\
\hline Alt 6 & 0,162 & 0,225 & 0,225 & 0,150 & 0,126 & 0,150 & 0,150 & 0,141 & $16,61 \%$ & 0,15 & 0,92 & & & & \\
\hline Alt 7 & 0,162 & 0,225 & 0,225 & 0,150 & 0,126 & 0,150 & 0,150 & 0,141 & $16,61 \%$ & 0,15 & 0,92 & & & & \\
\hline Alt 8 & 0,003 & 0,005 & 0,005 & 0,017 & 0,042 & 0,017 & 0,017 & 0,016 & $1,50 \%$ & 0,02 & 1,49 & & & & \\
\hline
\end{tabular}


Results obtained from pair-wise comparison matrix of criteria

\begin{tabular}{|c|c|c|c|c|c|c|c|c|c|c|c|c|}
\hline \multirow[b]{3}{*}{ PCT } & \multicolumn{12}{|c|}{ Normalized matrix } \\
\hline & PCT & $\mathrm{LHC}$ & DFS & SHC & TCM & $\mathrm{Wr}$ & $\mathrm{c}$ & $\mathrm{CV}$ & \multirow[t]{2}{*}{$\lambda \max$} & \multirow[t]{2}{*}{$\mathrm{CI}$} & \multirow[t]{2}{*}{ RI } & \multirow[t]{2}{*}{$\mathrm{CR}$} \\
\hline & 0,560 & 0,243 & 0,317 & 0,444 & 0,674 & $44,74 \%$ & 0,5450 & 1,2180 & & & & \\
\hline LHC & 0,062 & 0,027 & 0,005 & 0,010 & 0,025 & $2,58 \%$ & 0,0376 & 1,4561 & \multirow{4}{*}{ 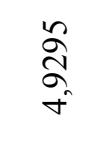 } & \multirow{4}{*}{$\frac{0}{0}$} & \multirow{4}{*}{$\begin{array}{l}\text { ลู } \\
\stackrel{-}{=}\end{array}$} & \multirow{4}{*}{$\begin{array}{l}\stackrel{\infty}{ \pm} \\
\\
0 \\
0\end{array}$} \\
\hline DFS & 0,080 & 0,243 & 0,045 & 0,013 & 0,032 & $8,26 \%$ & 0,0569 & 0,6886 & & & & \\
\hline SHC & 0,112 & 0,243 & 0,317 & 0,089 & 0,045 & $16,11 \%$ & 0,1095 & 0,6799 & & & & \\
\hline TCM & 0,187 & 0,243 & 0,317 & 0,444 & 0,225 & $28,30 \%$ & 0,2510 & 0,8869 & & & & \\
\hline
\end{tabular}

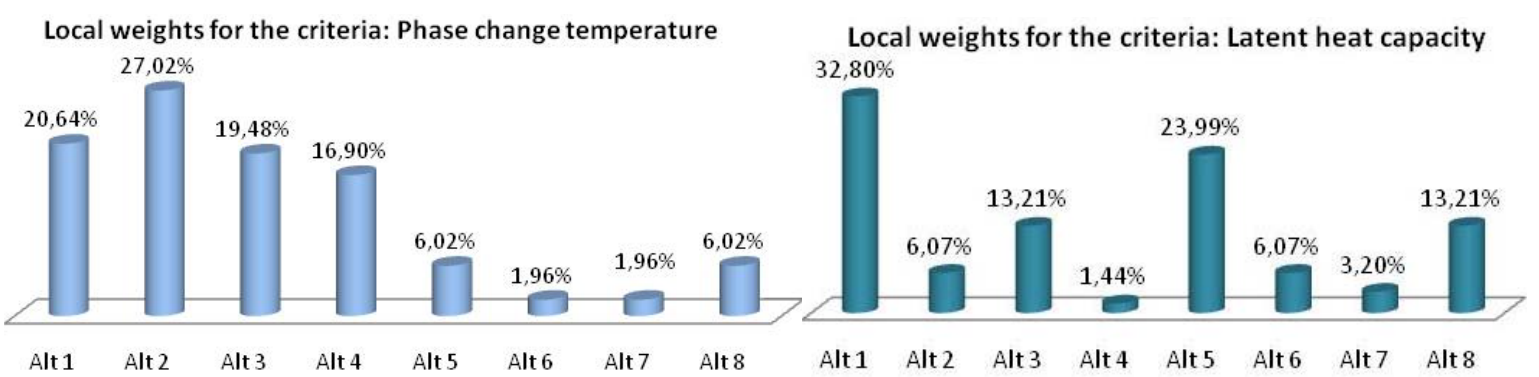

$\begin{array}{lllllllllllllllllll}\text { Alt } 1 & \text { Alt } 2 & \text { Alt } 3 & \text { Alt } 4 & \text { Alt } 5 & \text { Alt } 6 & \text { Alt } 7 & \text { Alt } 8 & \text { Alt } 1 & \text { Alt } 2 & \text { Alt } 3 & \text { Alt } 4 & \text { Alt } 5 & \text { Alt } 6 & \text { Alt } 7 & \text { Alt } 8\end{array}$

Local weights for the criteria: Density for solid Local weights for the criteria: Specific heat capacity
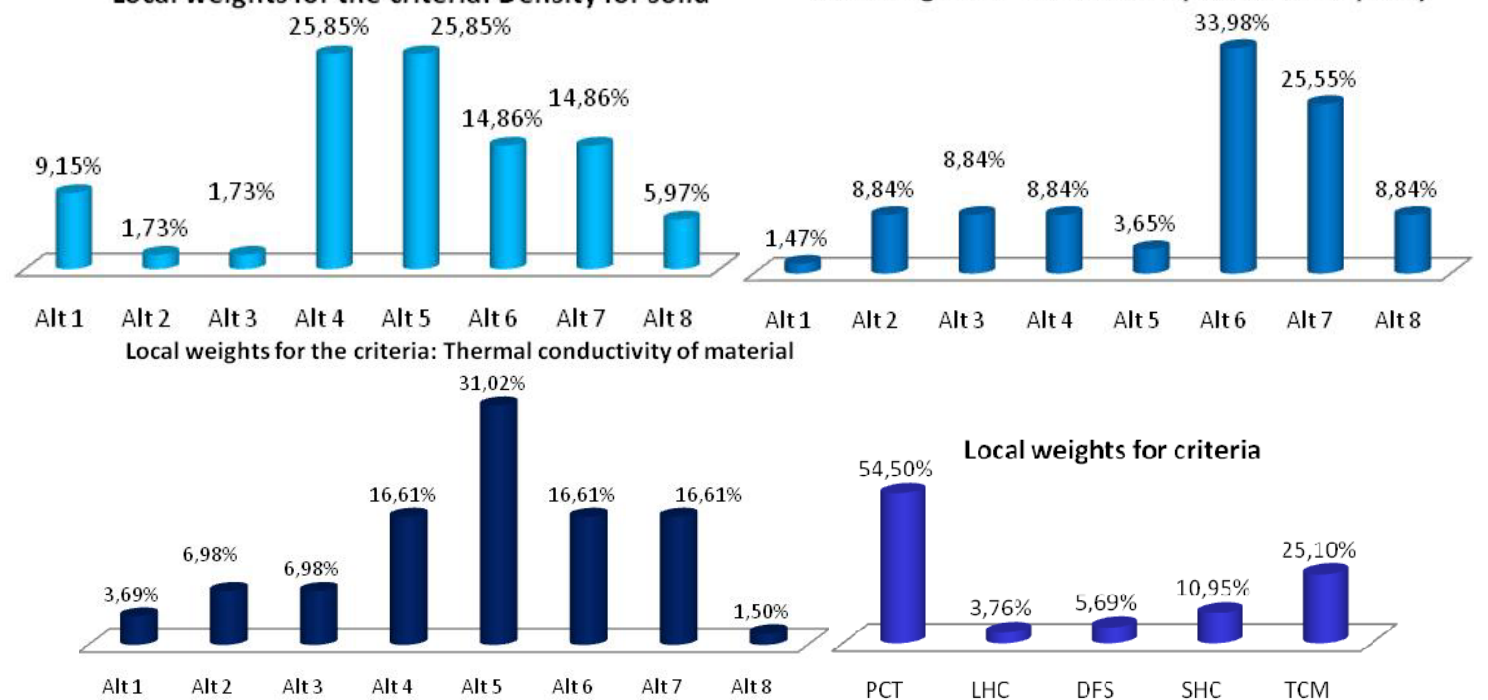

Fig. 2 - Local weights obtained

Final results for the case study considered

Table 5

\begin{tabular}{|c|lllll|r|r|}
\hline Alternative / Criteria & PCT & LHC & DFS & SHC & TCM & Global weights & Ranking \\
\hline Local weight & 0,5450 & 0,0376 & 0,0569 & 0,1095 & 0,2510 & & \\
Alt 1 & 0,2064 & 0,3280 & 0,0915 & 0,0147 & 0,0369 & 0,1409 & 3 \\
Alt 2 & 0,2702 & 0,0607 & 0,0173 & 0,0884 & 0,0698 & 0,1777 & 1 \\
Alt 3 & 0,1948 & 0,1321 & 0,0173 & 0,0884 & 0,0698 & 0,1393 & 4 \\
Alt 4 & 0,1690 & 0,0144 & 0,2585 & 0,0884 & 0,1661 & 0,1587 & 2 \\
Alt 5 & 0,0602 & 0,2399 & 0,2585 & 0,0365 & 0,3102 & 0,1384 & 5 \\
Alt 6 & 0,0196 & 0,0607 & 0,1486 & 0,3398 & 0,1661 & 0,1003 & 6 \\
Alt 7 & 0,0196 & 0,0320 & 0,1486 & 0,2555 & 0,1661 & 0,0900 & 7 \\
Alt 8 & 0,0602 & 0,1321 & 0,0597 & 0,0884 & 0,0150 & 0,0546 & 8 \\
\hline
\end{tabular}

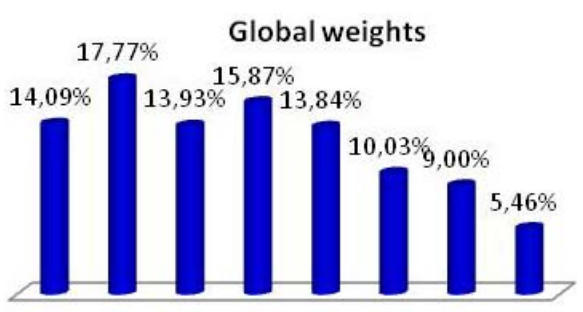

Alt 1 Alt 2 Alt 3 Alt 4 Alt 5 Alt 6 Alt 7 Alt 8

Fig. 3 - Global weights for the alternatives 
AHP method leads to the choice of Alt 2, i.e. PlusIce PCM S27 from EPS Ltd as the preferred alternative. The materials PlusIce PCM A22H (Alt 4) from EPS Ltd, Climsel C24 (Alt 1) from Climator and PlusIce PCM S23 (Alt 3) from EPS Ltd are the next best alternatives materials used for comfort application in buildings. The final selection is a result of the choices taken by the "decision makers", which is rather subjective ("extremely", "strongly" etc).

\section{Conclusions}

Using the analytic hierarchy process to prioritize and select the proper phase change material for comfort application in buildings facilitate us to obtain the desired results when the usage of latent heat storage systems is wanted. Usually, researchers use certain materials taking into account only their experience and the availability of a particular material. To improve the quality of decision regarding the choice of a particular type of material, we must consider several criteria and perform a rigorous selection of them. However, several alternatives must be considered and evaluated using different criteria for selection of the proper commercial PCMs for comfort application in buildings.

The AHP method helps us to choose the proper alternative for the problem studied, by prioritizing the alternatives according to the criteria set. For future research, with additional criteria, the AHP method can be reiterated.

\section{References}

[1] Liu, M., Saman, W., Bruno, F. (2012). Review on storage materials and thermal performance enhancement techniques for high temperature phase change thermal storage systems, Renewable and Sustenable Energy Reviews, Vol. 16, pp. 2118-2132

[2] Dincer I., Rosen, M.A., (2002). Thermal energy storage: storage and applications, John Wiley \&Sons, Vol. 57-59

[3] Rathod, M.K., Kanzaria, H.V. (2011). A methodological concept for phase change material selection based on multimple criteria decision analysis with and without fuzzy environment, Material and Design, Vol. 32, pp. 3578-3585

[4] Rodriguez-Ubinas, E., Ruiz-Valero, L., Vega, S., Neila, J. (2012). Applications of phase change material in highly energy-efficient houses, Energy and Buildings, Vol. 50, pp. 49-62

[5] Sharma, A., Tyagi, V.V., Chen, C.R., Buddhi, D. (2009). Review on thermal energy storage with phase change materials and applications, Renewable and Sustainable Energy Reviews, Vol. 13, pp. 318-345

[6] Abhat, A., (1983). Low temperature latent heat thermal energy storage: heat storage materials, Solar Energy, Vol. 30, No. 4, pp. 313-332

[7] Saaty, T.L. (2008). Decision making with the analytic hierarchy process, International journal services sciences, vol. 1, no. 1, pp. 83-98

[8] Datta, A., Ray, A., Bhattacharya, G., Saha, H. (2011). Green energy sources (GES) selection based on multi-criteria decision analysis (MCDA), International Journal of Energy Sector Management, Vol. 5, No. 2, pp. 271-286

[9] Socaciu, L.G. (2011). Studii si cercetari privind utilizarea teoriei fuzzy in cadrul procesului de dezvoltare a produselor pe baza cerintelor clientului, Teza de doctorat, Universitatea Tehnica din Cluj-Napoca.

[10] Ray,A., Sarkar, B., Sanyal, S. (2010). The TOC-based algorithm for solving multiple constraint resources, IEEE Transactions on Engineering Management, Vol. 57, No. 2, pp.301-310

[11] ***Climsel C24 (accessed may 2013), available at: http://www.climator.com/files/products/climsel-c24.pdf

[12] Koekenbier, S.F. (2011). PCM energy storage during defective thermal cycling, Design of the "Capacity Cube" and modelling of PCM pouches to trace the impact of incomplete thermal cycling, Thesis MSc-ME, Delft University of Technology.

[13]***PlusIce, (accessed may 2013), available at: http://www.pcmproducts.net/files/PlusICE\%20Range-2013.pdf

[14]***Rubitherm, (accessed may 2013), available at: http://www.rubitherm.de/english/index.htm

[15] Evers, A. (1989). Development of quantitative measure of the functionality of frame walls enhanced with phase change materials using a dynamic wall simulator, Thesis MSc in Arhitectural Engineering, Wichita State University, Wichita, Kansas

[16] Rouault, F., Bruneau, D., Sebastian, P., Ango, S.E., Lopez, J. (2012). Numerical modelling and experimental study of a box-section tube bunde thermal energy storage for free-cooling of buildings, The $12^{\text {th }}$ International Conference on Energy Storage, Innstock, available at:

http://hal.archives-ouvertes.fr/docs/00/80/50/28/PDF/Paper_Innostock_2012___INNO-SP-59.pdf, accessed may 2013

[17]***TEAP, (accessed may 2013), available at: http://www.teappcm.com/products.htm 